\title{
Narrativización mediática de la Operación Jaque y la construcción de la idea del fin del conflicto ${ }^{1 .}$
}

\author{
Media narrativization of the Operación Jaque and construction of the idea of the \\ end of the conflict.
}

\section{Ginna Mercedes Becerra Gómez \\ Julián Andrés Burgos Suárez ${ }^{3}$}

Becerra G. Ginna M, Burgos S. Julián A. miradas Nº13 - 2015. ISSN: 0122 994X Págs 41 - 54

Recepción: Mayo 12 de 2015

Aprobación: Septiembre 24 de 2015

Publicación: Diciembre 17 de 2015

\section{Resumen}

Las formas en que desde diferentes medios de comunicación se narraron los acontecimientos del 2 de julio de 2008, conocidos como la Operación Jaque, determinaron la manera en que la opinión pública colombiana entendió, para dicho momento, el fin de las FARC y por consiguiente, el final del conflicto armado. Se descubre que la idea del fin del conflicto surgida en dicho momento, es el resultado de una estrategia narrativa que hace posible entender que desde la Operación Jaque, la correlación de fuerzas en el conflicto armado cambió: porque de un relato centrado en las víctimas, se pasó a un relato centrado en los héroes. Así, el enfoque de la narrativización de acontecimientos se convierte en una propuesta de análisis de los modos en que las diferentes narrativas mediáticas elaboran el sentido de lo real y la memoria de lo pasado.

Palabras Clave: Narrativas mediáticas, narrativización, representación de la realidad, memoria, conflicto armado

\footnotetext{
1 El presente artículo es producto de los resultados obtenidos en la investigación Narrativización mediática de la Operación Jaque: Análisis de la narrativa mediática de la Operación Jaque y la construcción de la idea del fin del conflicto en el marco de la Maestría en Comunicación Educativa de la Universidad Tecnológica de Pereira.

2 Licenciada en Español y Literatura de la Universidad Tecnológica de Pereira, Magister en Comunicación Educativa de la Universidad Tecnológica de Pereira. Actualmente estudiante de Doctorado en Ciencias de la Educación (RudecolombiaCade UTP) ginna.becerra@utp.edu.co

3 Comunicador Social con énfasis en Comunicación Educativa de la Universidad Javeriana, Magister en Comunicación Educativa de Universidad Tecnológica de Pereira. Investigador del grupo Comunicación, educación y culturas y actualmente director del programa de Comunicación Social-Periodismo de la Universidad Católica de Pereira. julian. burgos@ucp.edu.co
} 


\begin{abstract}
In which forms from different media narrated the events of July 2, 2008, known as Operation Jaque, they determined the way in which Colombian public opinion understood, for that time, the end of FARC and therefore, the end of the armed conflict. It is discovered that the idea of the end of the conflict that emerged at that time, is the result of a narrative strategy that makes it possible to understand that since the Operation Jaque, the correlation of forces in the armed conflict has changed: because of a story focused on the victims, was moved to a story focused on the heroes. Thus, the focus of the narrativizacion of events becomes a proposal for analysis of the ways in which the different media narrative developed sense of the reality and the memory of the past.
\end{abstract}

Key Words: media narrative, narrativization, representation of reality, memory, armed conflicto

\section{Introducción}

La narración mediática de los acontecimientos sucedidos el 2 de julio de 2008 conocidos como la Operación Jaque, tienen que problematizarse, ya que después de lo relatado por los medios, la idea del fin del conflicto por vía militar era un hecho inminente para la opinión pública a tal punto que era una idea aceptada que un ejército valeroso de héroes, lo haría posible. Lo que se demostró con el tiempo es que tal cuestión nunca sucedió, pero avizorar todo esto en el creer común de la gente, fue posible gracias a la narrativa compulsiva sobre la Operación que elaboró un relato en el que la correlación de fuerzas en el conflicto armado, había cambiado: el Estado y su fuerza pública eran más fuertes que sus enemigos de la guerrilla.
La capacidad de generar representaciones de la realidad que tienen los medios de comunicación, como en el caso de la Operación Jaque, es el lugar donde se enmarca el problema de investigación. No se enfoca en las cualidades de dicha representación, ni en los abordajes políticos desde donde suelen ser leídas, sino desde la forma en que son elaboradas como relatos que construyen la realidad, esto es, desde un proceso denominado narrativización.

Existen muchas formas en que desde los medios se puede dar cuenta de la realidad, pero la forma privilegiada es el relato (Rincón, 2006:99). Existen en los medios dos tipos de relatos que también están presentes en otros ámbitos y son universalmente conocidos: los relatos de ficción y los de realidad. Sobre los primeros hay una amplia tradición de análisis que incluye la literatura, la semiótica, la estética del cine y el estructuralismo en general. Sobre los segundos, bien podrían incluirse los análisis periodísticos y los historiográficos, y una importante porción de cierto tipo de análisis literario. No todos estos análisis consideran el lugar del relato y la narrativa en las formas de abordar los textos, y no todos tienen como objetivo descubrir cómo se gestionan formas de representación de la realidad desde ellos. Teniendo en cuenta estos planteamientos, cuando se abordan relatos mediáticos que versan sobre la realidad, el concepto de narrativización es útil para mirar cómo se elaboran representaciones que constituyen relatos de sentido desde donde se gestiona socialmente el pasado y el presente.

Para efectos del análisis mediático de la narrativización, han de tenerse en cuenta tres cuestiones fundamentales. La primera de ellas establece que las acciones seleccionadas deben ser las que señalen contravenciones a las normas sociales establecidas, esto quiere 
decir, acontecimientos que expresan un conflicto contra un orden existente y que son presentados con una reflexión moral (Luhmann 2007:48). Seguido de esto, los acontecimientos deben dar cuenta de una acción que puede ser atribuible a un sujeto, es decir, se concentran en la persona y las acciones como modo de tipificación del acontecimiento, esto es, de inteligibilidad para el público (2007:50-51).

La segunda cuestión se refiere a la forma de tramar los acontecimientos seleccionados. Estos son puestos en una estructura secuencial que los encadena uno con otro, de modo que se presentan como reveladores de un sentido final (White,1992:30). Para esto se emplea un modo de ficción que los hila de tal forma que su comprensión última se revela como si cada episodio estuviera orientado a desarrollar una idea resultante, total y explicativa de lo sucedido (White, 2005:16). El relato de los acontecimientos se hace de acuerdo a un modo de ficción particular que puede ser: romántico, trágico, cómico o satírico (2005:18).

Y la tercera cuestión, después de la selección y el tramado, es la relacionada con su tropología. Los acontecimientos que se ponen en el relato son susceptibles de analizarse bajo una tropología que revela una forma particular de configuración de la realidad (White, 2003:44) Los tropos básicos con los cuales se representa la realidad narrativamente son: la metáfora, la metonimia, la sinécdoque y la ironía (2003:42).

Planteada la naturaleza del problema, los objetivos de la investigación fueron establecer los relatos de la Operación Jaque que elaboraron los medios de comunicación, y determinar las estrategias de narrativización que utilizaron para construir la idea del fin del conflicto. De tal forma que la investigación se centró en el análisis de los medios y sus relatos, ya que lo que se analizó fue el contenido narrativo de ciertos programas de televisión. Lo que se realizó fue un análisis narrativo basado en la lógica de las acciones, salvo que no pretendió solo desentrañar la estructura del texto, sino que buscó descubrir cómo se gestó un relato que da cuenta de lo real; para ello se emplearon algunas categorías del análisis de los relatos históricos aportados por White, y que guardan coherencia metodológica con los objetivos propuestos (White, 1992:47,48).

La investigación se realizó tomando como material de análisis las producciones mediáticas realizadas entre el mismo año del episodio, 2008, y el año 2010, siendo en total 4 documentales y una serie de ficción inspirada en hechos reales, producidas por empresas informativas colombianas, anglosajonas y españolas, como son: Caracol, RCN, Discovery Channel, National Geographic y Paraíso Picture, así como uno de producción propia del Ejército Nacional de Colombia; todas estas con un alto grado de circulación en canales y medios nacionales.

\section{Materiales y métodos}

En función del análisis narrativo que se debe hacer para reconstruir en los relatos mediáticos la realidad representada, es necesario aplicar una metodología que le de base empírica a dicha deconstrucción. El método que mejor guarda relación con el propósito, es del Análisis de la Lógica de las Acciones de Todorov. Se basa en el análisis de proposiciones que son las unidades de la acción (un alguien que realiza algo para alcanzar un objetivo en la escena) (1971:74). Nótese que esta decisión metodológica pone en el centro del análisis la acción de un héroe, lo que facilita el análisis de los modos de ficción y está en relación con los principios morales de selección. 
La unidad de análisis de los relatos que se tomará es la frase, ya que encierra el núcleo básico de construcción del relato como un alguien que hace algo para conseguir un objetivo (Bal, 1996:19), es decir, el principio de acción de toda narración (Ricoeur, 1995:21-22) que equivale a la proposición o a la micronarración (Todorov,1971:74) y que también es aplicable a la comprensión global del relato (García, 2001:102). Por tal motivo y para efectos metodológicos, los acontecimientos fueron descritos y enunciados como frases con sujeto, verbo, predicado y objeto (Bal, 1996: 25). Esto se complementó con la distinción del tipo de sujeto de la acción (protagonista, víctima, antagonista, ayudante, narrador o comentador), de la ubicación temporal y espacial de cada proposición, de los obstáculos que enfrentó y de la especificación del criterio de selección del acontecimiento de acuerdo al orden moral, esto es, que se indicó si el acontecimiento se referencia en función de la contravención de normas existentes, y sobre qué normas explícitas o implícitas es que se da el hecho.

El material que se analizó estuvo conformado por los documentales y series de televisión nacional y extranjera que trataron el tema de la operación Jaque desde que sucedieron los acontecimientos en 2008 hasta el 2010, año en que inició esta investigación. Los documentales y series de televisión seleccionados son los que más difusión mediática tuvieron dentro del ámbito Colombiano y son los que fueron más fácil de recuperar. Los documentos audiovisuales que se analizaron fueron son los siguientes:

- 2008 Noticias RCN: especial de una hora con imágenes inéditas de lo sucedido.

- 2008 National Geographic "Chanel: documental "Operacion Jaque".
- 2009 Discovery Chanel: documental titulado "El Rescate Perfecto".

- 2009 Ejército Nacional: documental titulado Soldados sin Coraza.

- 2010 Caracol televisión: miniserie dramatizada producida por Paraíso Pictures llamada "Operación Jaque".

En esta parte inicial del análisis se desarrolló el primer objetivo específico de la investigación, que busca identificar los acontecimientos seleccionados por los medios desde donde se configuran los relatos mediáticos de la Operación Jaque. Se pretendió establecer los sujetos a los cuales se les atribuye distintas acciones que despliegan el relato, así como la razón por la cual dichos hechos son entendidos como contravenciones sociales significativas, es decir, que expresan un conflicto o contradicen un orden social existente.

Se establecieron las micronarraciones que componen el relato de cada programa, describiéndolas como una frase en donde un sujeto realiza una acción específica para lograr un objetivo. Así, cada programa se dividió en un número tal de micronarraciones, cada una de las cuales desarrolla una acción atribuible a un sujeto determinado, y que tiene un complemento en el que pueden o no estar involucrados otros sujetos de forma pasiva. Los sujetos a su vez, se preestablecieron de acuerdo a su rol lógico dentro del relato como protagonistas, antagonistas, víctimas y ayudantes. Esto permitió identificar cuántas veces son sujetos en la acción los diferentes actores dentro de cada relato en su modo pasivo y activo.

El siguiente cuadro muestra el número de micronarraciones que se halló en cada producto audiovisual, y las referencias a cada sujeto en el relato para cada una de ellas. 


\begin{tabular}{|c|c|c|c|c|c|}
\hline : & 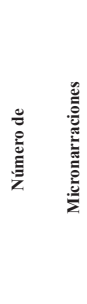 & 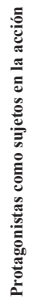 & 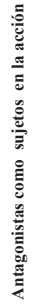 & 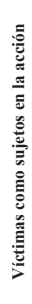 & 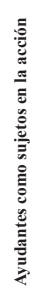 \\
\hline $\begin{array}{c}\text { Operación } \\
\text { Jaque. RCN }\end{array}$ & 41 & 34 & 5 & 5 & 3 \\
\hline $\begin{array}{l}\text { Operación } \\
\text { Jaque. NG }\end{array}$ & 43 & 22 & 5 & 19 & 20 \\
\hline $\begin{array}{c}\text { El Rescate } \\
\text { Perfecto. DC }\end{array}$ & 34 & 15 & 9 & 19 & 22 \\
\hline $\begin{array}{l}\text { Soldados sin } \\
\text { Coraza. }\end{array}$ & 18 & 12 & 4 & 3 & 8 \\
\hline $\begin{array}{c}\text { Operación } \\
\text { Jaque, la serie. }\end{array}$ & 97 & 44 & 50 & 83 & 49 \\
\hline
\end{tabular}

Número de micronarraciones en cada relato mediático

Para los análisis de los modos de tramar se desarrolló el segundo objetivo específico de la investigación que busca definir los modos de ficción usados para la construcción de los relatos mediáticos de la Operación Jaque. Se trataba de describir la lógica de las secuencias que despliegan los sujetos del relato, así como los obstáculos a los que se enfrentan, para explicar las estructuras que ordenaron los acontecimientos seleccionados en cada documental con el que se construyó un sentido sobre lo sucedido. Esas estructuras corresponden a los modos de tramar, los cuales White establece como romántico, trágico, cómico y satírico.

De las micronarraciones en cada relato mediático se tomaron las que tuvieron por sujeto de la acción a los actores que el análisis de la primera categoría mostró como significativos, es decir, a los protagonistas (oficiales de inteligencia del ejército que participaron en la operación), excepto en el caso de Operación Jaque, La Serie, en donde también se tomaron las acciones que realizaban las víctimas, por ser significativas para dicho relato.
Posteriormente se agruparon las micronarraciones relativas a los protagonistas de acuerdo a la semejanza de los verbos para establecer un denominador común que permitiera construir una proposición que condensara las acciones relativas a los protagonistas y que describiera el sentido de la secuencia; y luego se identificaron los obstáculos o metas de la acción en cada grupo de micronarraciones. Por último, se trazó una línea de continuidad lógica, atendiendo a la propuesta de análisis de Todorov, entre los verbos relativos a los protagonistas que describen las secuencias de acciones realizadas por los protagonistas y los obstáculos encontrados, así se pudo establecer el modo de tramar en cada relato mediático.

En el último momento del análisis se desarrolló el tercer objetivo de la investigación que es determinar los tropos usados por los relatos mediáticos para representar la Operación Jaque. Se trataba de establecer la relación tropológica que permite encadenar narrativamente los acontecimientos, y que de acuerdo a lo planteado por White, puede ser metafórica, metonímica, sinecdóquica o irónica. Estos encadenamientos se dan alrededor de ideas-red, que son secuencias narrativas que tropológicamente unen un hecho a otro, y que desarrollan el sentido de lo que el relato quiere comunicar como lo real-acontecido, expresado mediante una proposición que puede estar explícita o no en lo narrado.

Se tomaron las listas de micronarraciones de cada relato mediático y a cada una se le asignó un número. Empezando por el acontecimiento número uno, se estableció el tipo de relación que había con el acontecimiento número dos, y de acuerdo a un código de colores, se identificó esta relación con uno de los 
tropos propuestos en la teoría. Luego se tomaba el tercer hecho y se identificaba el tropo que signaba la relación de este con el segundo acontecimiento. Así, hasta llegar al último hecho que compone la lista de micronarraciones. De esta manera se hacia el análisis vertical que revela la tropología del relato. Esto permitió encontrar que habían acontecimientos específicos que tenían dos funciones: desencadenar diferentes ideas-red o condensar diferentes ideas-red. El resultado fue la concepción del relato como un trenzado de ideas-red interiores que van elaborando el sentido de todos los acontecimientos en ellos puestos.

\section{Resultados y discusiones}

Estos tres momentos de la metodología se realizaron de forma consecutiva, logrando que se desplegaran las categorías propuestas al análisis de los relatos mediáticos, de modo que lo hallado en un momento de análisis sirvió para orientar el siguiente momento. Al final se logró obtener información de cada una de las categorías, con la que fue posible desentrañar los modos en que se representaban los acontecimientos de la Operación Jaque en los diferentes productos mediáticos analizados.

\section{Atribución del acontecimiento a un sujeto}

Con respecto a la primera subcategoría de análisis que nutre la dimensión de selección de los acontecimientos en el proceso de narrativización mediática, se pudo apreciar que los hechos relativos a la Operación Jaque se empiezan a configurar desde el desequilibrio de las relaciones lógicas de los actores en los relatos. Esto significa que los antagonistas no desarrollaron acciones propias de un antagonista, como en el caso de El Rescate Perfecto, o Soldados sin Coraza, en donde estos no tienen una presencia amplia y coherente con su rol.
También se manifestó mediante la igualación de las funciones de unos actores para dar predominancia a un tercer actor, que puede convertirse luego en el centro del relato, como es el caso del documental del Ejército Nacional en donde de acuerdo a las acciones realizadas, los victimarios aparecen en una función de oponentes, tanto como los mismos antagonistas de la historia. Así mismo, se identificó una transmisión de roles en los actores para hacer relevante las acciones de otro actor, como en el caso de Operación Jaque, La Serie, en donde los ayudantes se convirtieron en oponentes del relato, pero diferentes a los antagonistas, para remarcar el sentido de antagonistas y de ayudantes de otros actores dentro del relato.

El descentramiento de ciertas funciones actorales dentro del relato para privilegiar las acciones de unos actores específicos, señala un rasgo típico de la narrativización mediática de la operación Jaque en lo que concierne a los criterios de selección de los acontecimientos. Esto quiere decir que se han seleccionado los acontecimientos que sirven para destacar las acciones de unos personajes sobre otros, ¿cuáles son esas acciones y cuáles esos personajes? Esto se resuelve atendiendo al segundo criterio de selección de los acontecimientos que tiene que ver con la ruptura del orden social existente.

\section{Acontecimientos como contravención de un orden social existente.}

Las acciones que se seleccionaron son las que remarcan una idea que es recurrente en los productos analizados: mediante un trabajo impecable en materia de estrategia militar, se ha logrado la misión imposible de liberar a los secuestrados. Los personajes que se minimizaron con las acciones seleccionadas fueron las víctimas y los antagonistas, y los que se maximizaron fueron los protagonistas y los ayudantes, 
obviamente en una relación de vencidos y vencedores.

Es significativo que los acontecimientos seleccionados para ser contados tuvieran como sujetos de la acción, en forma activa $\mathrm{y}$ en un mayor número, a protagonistas y ayudantes, es decir, a los oficiales de inteligencia del ejército que participaron en la operación de rescate, y a los altos mandos militares, los ministros y el presidente. $\mathrm{Y}$ del mismo modo, es significativo que sus roles se descentren de lo que sería un comportamiento lógico dentro de la razón narrativa, para reforzar la predominancia de dichos actores.

Esto significa, en otras palabras, que el relato mediático de la Operación Jaque no es una narración sobre el secuestro, sino sobre las acciones valerosas del ejército. Minimizar las víctimas y los antagonistas, y maximizar los protagonistas y los ayudantes es empezar a narrativizar los acontecimientos sucedidos alrededor de la Operación Jaque sobre la idea del triunfo militar, como la hipótesis de comprensión del evento más plausible de acuerdo al modo en que ha sido relatado. Y si se tiene en cuenta que los acontecimientos seleccionados tuvieron un factor en común en su carácter de eventos contradictorios de un orden social existente, queda mucho más claro cómo se está dando ese proceso de narrativización.

Seleccionar un acontecimiento es hacer una referencia no explícita a un orden social existente que no se nombra, porque está supuesto, ya que si el acontecimiento se cuenta es porque ha roto lo convencional, de lo contrario no sería significativo para la narración. De alguna manera se narra sólo aquello que se considera extraordinario y diferente porque requiere ser comprendido. En ese orden de ideas, es común a todos los relatos mediáticos analizados, que el orden social que se quebrantó es el de la incapacidad histórica del ejército de derrotar militarmente a las FARC. Esta incapacidad histórica es el contexto común a los relatos que justifica todas las estrategias narrativas empleadas en los cinco programas analizados, y que se manifiesta bien sea como una incapacidad técnica del ejército que carece del saber y los medios para realizar operaciones exitosas; una incapacidad humana de las fuerzas armadas que no tiene soldados valerosos y comprometidos con su deber, y una incapacidad política que no ve posible un rescate militar después de una serie de liberaciones humanitarias y de fallos militares de rescate.

\section{Modos de tramar.}

En esta subcategoría se encuentra de manera significativa que todos los relatos mediáticos tramaron los hechos atendiendo al modo de ficción romántico, el cual define White como el modo en que los acontecimientos se cuentan en función del drama de un héroe que debe redimir una situación, imponerse contra el mal o contra las fuerzas adversas, generando identificación con él mismo y su trayectoria (White, 2005:19). Cuando los acontecimientos están tramados bajo el modo de ficción romántico, el relato muestra como se transforma por acción de un héroe, un estado de cosas que parecía inmutable. El análisis arrojó además, que no todos los modos de tramar a pesar de ser románticos, lo eran de la misma manera. Se encontró que el modo de tramar romántico era: memorable, épico y redentor, dependiendo de la manera en que se conjuga la travesía del héroe con los obstáculos presentados y el fin último de las acciones.

Un relato romántico-memorable será aquel en el que las acciones que el héroe realiza para trasformar una situación inicial adversa para un actor del relato, se narran para que el protagonista trascienda el relato 
y pase a la historia. Todas las acciones cobran sentido en función de dicha elevación del héroe, y se comprenden en el relato como pasos previos para la gloria, como preparación para la inmortalidad del protagonista, más que para la memoria de lo sucedido o lo aprendido. En la narración el acento está en el héroe, pues nunca se duda de él y de su capacidad de superar las pruebas, las cuales nunca están por encima del poder del protagonista.

Un relato romántico-épico, en esa misma dirección, es aquel en donde se muestra la travesía de un héroe que resuelve una situación inicial, pero que no pasa a la historia, sino que sus acciones se consideran hazañas increíbles por el tipo de obstáculos que debió enfrentar y superar, a los cuales efectivamente logró sobreponerse, pese a que estos se presentan superiores a las posibilidades de los protagonistas mismos. El acento del relato está en la narración minuciosa de las peripecias del héroe para sobreponerse a los obstáculos y así lograr resolver la situación inicial.

$\mathrm{Y}$ un relato romántico-redentor es aquel en donde la travesía del héroe resuelve la situación inicial adversa de otro actor del relato, protagonista/víctima, que por sus propios medios es incapaz de resolver y se ha rendido a la misma. El héroe debe superar los obstáculos que aparecen, muchas veces superiores a él, para que al final logre redimir al protagonista/ víctima. En este relato el acento está en la complejidad de la situación adversa que se debe resolver y en los obstáculos que retan al héroe para redimir a la víctima, objetivo final de su travesía. Este tipo de relato romántico necesita la presencia de un protagonista/víctima que debe ser rescatado, y cuya fatiga justifica la acción salvadora del héroe.

\section{Obstáculos.}

Dado el modo de ficción encontrado en los relatos mediáticos analizados, el análisis de los obstáculos se torna importante ya que estos detallan la travesía del héroe en cada narración; y dependiendo de su origen y grado de detalle, estos ayudan a configurar el tipo de relato romántico que se presenta en los documentales.

En lo que respecta al origen de los obstáculos, las micronarraciones analizadas mostraron que estos pueden ser externos o internos. Se consideraron los obstáculos externos como aquellos impedimentos que se le presentaban al héroe para lograr sus objetivos que provenían de las acciones de otros actores del relato ya sea de forma directa, cuando su propósito fundamental es oponerse al héroe, o de forma indirecta cuando por desempeño de su rol, terminaban oponiéndose a las acciones del protagonista.

Los obstáculos externos también se presentaron como impedimentos que surgieron de las acciones mismas de los protagonistas por lograr sus objetivos, por ejemplo cuando para lograrunas actuaciones convincentes que pudieran engañar a las FARC, el equipo de inteligencia debía aprender a actuar e improvisar, lo que se constituyó en un obstáculo externo relativo al logro de sus objetivos.

Los obstáculos internos hacen referencia a los impedimentos que enfrentaban los protagonistas y que provenían ya no de acciones o actores externos a ellos, sino de estados internos que surgían frente a la presencia de situaciones desafiantes en el relato. Se configuraba un obstáculo interno cuando por efecto de dichas situaciones, los protagonistas reflexionaban sobre sí mismos y su propia capacidad de superación del obstáculo, configurando un estado interno de duda o temor frente 
al desarrollo de las acciones. Cuando no se daba este momento de reflexión, la acción desafiante significaba solo la presencia de un obstáculo externo que desafiaba a los protagonistas.

También se consideraron obstáculos internos las situaciones de discusión o de división al interior de los protagonistas, cuando las situaciones desafiantes originaban divergencias en los modos de proceder para superar los obstáculos, lo que significaba atentar contra la capacidad de resolución que creían tener los protagonistas, elevando de modo inverso, el sentido de valentía que sobre ellos configuraban las narraciones.

De este modo, en los relatos mediáticos cuya trama se presentó alrededor del modo romántico-memorable, se encontraron que los obstáculos eran todos de tipo externo, lo que bien coincide con el acento de este modo de tramar que se centra en la figura del héroe como figura histórica que trasciende el relato mismo. En los relatos mediáticos del tipo romántico-épico los obstáculos que se presentaron fueron tanto de tipo externo como de tipo interno. Esto remarca el acento del relato centrado en la minuciosidad de las peripecias que hace el héroe para resolver la situación adversa, ya que esto obliga a detallar mejor los impedimentos que debe franquear el héroe y también ayuda a mostrar como el héroe percibe que los obstáculos son superiores a él, mostrándolo en una situación de confrontación que hace mucha más agónica y valiente su travesía. Y los relatos de tipo romántico-redentor presentaron obstáculos externos e internos pero de forma consecutiva, esto quiere decir que ante la presencia de un impedimento de tipo externo, el protagonista entraba siempre en confrontación, lo que daba paso a la configuración de un obstáculo interno que remarcaba el acento en la complejidad de la situación a resolver por parte del protagonista/héroe.

Esta forma consecutiva en que aparecieron los obstáculos también se presenta para el protagonista/víctima de este tipo de relato, pero a diferencia del protagonista/ héroe, la confrontación que sufre el primero terminó en derrota, mientras que la confrontación que sufre el segundo terminó en el convencimiento de su capacidad de superación, lo que imprime en el relato un sentido agónico a la acción del héroe. Así, mientras que los obstáculos vencen al protagonista/víctima, los obstáculos hacen más fuerte al protagonista/héroe, y si su travesía consiste en superarlos, pese a la amenaza que implican, no solo resuelve la tragedia de la víctima, sino que con esas mismas acciones, se vuelve narrativamente un héroe redentor.

\section{Análisis de la tropología.}

De acuerdo al papel que cumplen las ideasred en la estructuración narrativa de los relatos, se especifica entonces las formas típicas de los encadenados que fueron desarrollados a partir de la metonimia, la metáfora, la sinécdoque y la ironía; con ello, se explican las columnas tres y cuatro de los cuadros referenciados.

\section{Dominancia tropológica metonímica.}

En primer lugar, hay que decir que el tropo más frecuente en la construcción de ideasred fue el de la metonimia, el cual presenta los acontecimientos en relación de causa y consecuencia, como pertenecientes a un todo al que explican. Lo que esto significa es que los hechos de la operación Jaque fueron preferentemente relatados en un esquema cronológico-temporal, como si el relator quisiera ubicarse en la posición de testigo que ha visto lo sucedido y trata de contarlo tal y como se presentó. 
Esto se justifica si se tiene en cuenta que los relatos mediáticos aparecieron en un tiempo relativamente cercano a la fecha de la operación ${ }^{1}$ y que se tiene como principal soporte de lo sucedido las grabaciones audiovisuales tanto del Ejército como de la guerrilla, en las que se registran cómo fueron los hechos minuto a minuto durante el operativo. Esto constituye la base de la dominancia del tropo metonímico en la conformación narrativa de las ideasred, ya que se logró la configuración de la operación como evento cuya superlatividad es comprobada por el grado de detalle que se puede alcanzar de él, el que solo es posible por el conteo cronológico de los hechos que lo desplegaron.

A lo que alude la otra condición de una secuencia narrativa conformada desde la metonimia, y que se basa en mostrarlos como pertenecientes a un todo el cual describen, se vio reflejado en el hecho de que estos encadenados cronológicos o consecuentes se han vuelto parte constitutiva de todos los relatos sobre la operación, ubicándolos como la parte resolutiva de la trama o lugar de desembocadura de los diversos antecedentes narrativos de los hechos, los cuales, sí son diferentes en los relatos analizados.

\section{Dominancia tropológica sinecdóquica y metafórica.}

Las otras figuras dominantes en la configuración tropológica fueron la sinécdoque y la metáfora, las cuales se definieron como representaciones que muestran los acontecimientos como pertenecientes a un todo, pero que para el caso del primer tropo, más que describirlos, los integra simbolizándolos, y para el caso del segundo, los representa mediante una analogía narrativa en sus diferencias o semejanzas. La primera característica de estos tropos es que se presentaron en secuencias narrativas en las que se venía dando un encadenado metonímico, pero que en algún momento, se anudaba a otro acontecimiento o a otro encadenado que rompía el esquema cronológico-temporal, y que elevaba la narración a un esquema que operaba más en la vía de desarrollo episódico de una idea más abarcante: bien sea como comparación o narración paralela de episodios, como fue el caso de las ideas-red metafóricas, o ejemplificación o explicación de una mayor, en el caso de las ideas-red sinecdóquicas.

Esto que se ha denominado como idea más abarcadora, no es otra cosa más que el rótulo o la denominación del sentido que los acontecimientos secuenciados expresan, y que es tomado de una parte o de una expresión del relato mismo, porque también se narra en la historia, es decir, está presente en la diégesis; es por lo tanto, un acontecimiento que se ha elevado a la idea de acontecimiento-global que hace posible el sentido. Son estos acontecimientos-globales los que en buena medida, equivalen a los acontecimientos condensadores y detonadores. Por esta circunstancia, la dominancia tropológica de la sinécdoque y la metáfora estuvo en poder anudar ideas-red en un esquema de acontecimiento-global que pone a los hechos seleccionados a explicarse unos con otros en la forma antes mencionada de desarrollo episódico de una idea más abarcadora, la cual, hacen posible que emerja el sentido propio de los hechos de la operación que cada relato quiso imprimir en ellos.

Fue mediante la metáfora y la sinécdoque que se pudieron anudar al relato mediático de la Operación otros acontecimientos diferentes a los de la cadena metonímica, y que en este ejercicio de narrativización, le dio a cada relato un sentido particular, como relato heroico, como relato que muestra la efectividad de la estrategia del gobierno, 
o como relato trágico del secuestro, diferenciando con ello, las versiones sobre lo sucedido el 2 de julio de 2008, es decir, de lo real-acontecido.

\section{Dominancia tropológica irónica.}

En lo que respecta a la ironía como tropo base de ideas-red, los análisis mostraron que fue empleado en solo tres de ellas, y en solo dos relatos mediáticos. Este se entiende como un paso a un orden de los acontecimientos que no es lógico de acuerdo a la secuencia de acciones en el relato, y que por consiguiente, la representación se muestra como absurda o paradójica.

Es decir, el uso del tropo de la ironía en la constitución de secuencias narrativas para la conformación de ideas-red, mostró que unos acontecimientos consecuentes no tienen nada que ver con sus antecedentes, pero esa estrategia de narrativización que efectivamente los pone en relación, los hace parecer sorprendentes, reveladores o inesperados, configurando con ello una dimensión de inusualidad narrativa en el relato mismo; no en vano, este tropo anudó ideas-red en donde los acontecimientos relativos al temor y a la controversia por un desenlace armado que resuelva el drama del secuestro, fueron conjurados con los hechos del operativo militar a los que son conectados.

\section{Conclusiones}

Para el caso de los eventos sucedidos el 2 de julio de 2008 conocidos como la Operación Jaque, su narrativización ha posibilitado elaborar un sentido de la realidad sobre el conflicto interno colombiano que para el momento histórico en que sucedieron los hechos, parece bastante creíble: avizoraba el fin del conflicto. Los relatos mediáticos que mediante estrategias de narrativización dieron cuenta de la Operación Jaque, pronosticaban un cambio en la correlación de fuerzas de la guerra interna colombiana, la cual desde el punto de vista de lo relatado, estaba próxima a terminar.

La forma de tramar presente en todos los relatos fue la del modo romántico, que se caracteriza por describir la travesía de un héroe por cambiar una situación que parecía inmutable, en donde los obstáculos a superar muestran las peripecias que debe hacer el héroe para superar las adversidades, imponerse a ellas, y cambiar la historia. Esto mismo fue lo que se encontró en los análisis de los modos de tramar en los cinco relatos mediáticos. De este modo, la idea de fin del conflicto tiene sustento narrativo, pero requiere precisar su sentido, que es en sí, el propósito del proceso de narrativización. Aquí es donde la tropología viene a sumar y a fijar la idea última de los relatos mediáticos. Para entender cómo es que la tropología fija el sentido en la estructura narrativa dentro de un proceso de narrativización, hay que pensar que el proceso de narrativización de la operación Jaque se ha dado en dos capas: la primera de ella contiene un núcleo narrativo básico compuesto por los acontecimientos que describen los instantes mismos de la operación de rescate y que son comunes a los cinco relatos analizados. Esta capa contiene el esquema cronológicotemporal que describe minuto a minuto como fue el operativo de rescate que como ya se dijo, está apoyada en imágenes reales que atestiguan cómo se desarrollaron los hechos el día de la operación. Esta cronología aparece siempre al final de los relatos mediáticos y está conformada desde la metonimia, ya que coloca los hechos uno como consecuencia de otro, pues es la lógica temporal de su narración así lo exige. Esta capa también contiene parte del sentido, ya que el esquema cronológicotemporal determina en buena medida que el tramado escogido haya sido el romántico en todos los casos, pues se tiene el testimonio 
audiovisual de las peripecias del héroe -los héroes en este caso- que es imposible excluir ya del proceso de narrativización.

La segunda capa es la que va a completar el sentido final de los relatos en el ejercicio de su narrativización. Si bien el esquema cronológico-temporal se construye sobre la base de la metonimia, determinando un núcleo de acontecimientos que se deben escoger siempre que se hable de la Operación, y derivando de ellos un modo de tramarlos (que para el caso es el romántico con su tipología respectiva), como encadenado metonímico aún se debe mostrar cuál es ese "todo" al cuál los acontecimientos de dicho núcleo pertenecen y explican. Ese "todo" es el que emerge en la segunda capa, y es el que permite anudar los demás acontecimientos que aparecen en los relatos mediáticos, los cuales varían en cada uno de ellos. Este "todo" es el que se configura desde lo real-acontecido como el sentido de cada relato mediático, expresado en un acontecimiento-global dado por una particular dominancia tropológica y responsable de cada una de los énfasis en el modo de tramar los acontecimientos. En el siguiente esquema se especifica como el sentido de lo real-acontecido va cambiando en cada relato mediático:

\begin{tabular}{|l|l|}
\hline Relato Mediático & Sentido de lo real-acontecido \\
\hline $\begin{array}{l}\text { Operación Jaque. } \\
\text { Especial RCN }\end{array}$ & $\begin{array}{l}\text { Una odisea militar - los solados como } \\
\text { verdaderos héroes de la patria. }\end{array}$ \\
\hline $\begin{array}{l}\text { Operación Jaque. Nat } \\
\text { Geo }\end{array}$ & $\begin{array}{l}\text { Las acciones del ejército son acciones } \\
\text { de una dimensión épica. }\end{array}$ \\
\hline El Rescate Perfecto & $\begin{array}{l}\text { La controversia y el temor al secuestro } \\
\text { - Estrategia militar exitosa que cuenta } \\
\text { con aliados estratégicos. }\end{array}$ \\
\hline Soldados Sin Coraza & $\begin{array}{l}\text { Amor y gloria al ejército por la misión } \\
\text { realizada. }\end{array}$ \\
\hline $\begin{array}{l}\text { Operación Jaque. La } \\
\text { Serie. }\end{array}$ & $\begin{array}{l}\text { El secuestro como la tragedia de } \\
\text { Ingrid y la evidencia del conflicto } \\
\text { colombiano- La estrategia de mano } \\
\text { dura contra el terrorismo de Uribe } \\
\text { puede cambiar el estado de la guerra. }\end{array}$ \\
$\begin{array}{c}\text { Progresión de lo } \\
\text { real-acontecido en la } \\
\text { narrativización mediática } \\
\text { de la operación Jaque }\end{array}$ \\
\cline { 2 - 2 } \\
\hline
\end{tabular}

En este esquema se puede ver que el sentido de lo narrado es diferente en cada relato mediático. A cada proposición que expresa el sentido, se llega aplicando la dominancia tropológica a lo realacontecido, estableciendo para el caso de la metáfora dos ideas que se comparan, o para el caso de la sinécdoque, una idea superior. Así que en la segunda capa se establece ese "todo" diferenciador desde donde la primera capa -metonímica- completa su sentido último.

El esquema revela que en los cinco relatos mediáticos analizados, la Operación Jaque ha tenido un sentido diferente en cada momento. Para el primer relato, la Operación es una odisea militar, por ende, los soldados deben ser considerados héroes de la patria; en este relato los acontecimientos se cuentan desde las horas previas al operativo de rescate. En el segundo relato, el sentido se establece como acciones épicas del ejército, y los acontecimientos se relatan dando antecedentes de la guerrilla y de algunos secuestros. Para el tercer relato, se introducen dos episodios que no estaban contemplados en los dos primeros programas: la controversia que existía en el país por el temor de un rescate militar, que se narra referenciando los episodios de los fracasos en intentos de rescate anteriores, y las revelaciones del apoyo norteamericano en la operación. Aquí el sentido tiene que ver con el temor al secuestro, y la estrategia exitosa que se logra gracias a los aliados.

El cuarto relato da elementos inéditos de la preparación que revelan el verdadero origen de la idea de engaño, ya no como una estrategia que viene de la unidad ejército/gobierno, sino que cuenta cómo dentro de él surgió desde los mandos medios que fueron convenciendo a sus superiores de abajo hacia arriba, hasta llegar al presidente, lo que perfectamente justifica el sentido que en él se da de la Operación Jaque como motivo de amor 
y gloria al ejército. Y el quinto relato, el único que utiliza recursos de la ficción para llenar los vacíos narrativos, relaciona acontecimientos mucho más atrás en el tiempo: hasta el momento del secuestro de Ingrid Betancourt, y mucho más amplio en el contexto social: poniendo la operación Jaque en el horizonte de la política antiterrorista del presidente Uribe (20022010), y en el de la guerra interna que libra Colombia; de este modo su sentido tiene que ver con la eficacia de la estrategia militar de Uribe que pone fin al drama del secuestro, vivido desde el periplo de Ingrid Betancourt $^{2}$, y que cambia la relación de fuerzas en el conflicto, presagiando ya el final de la guerra interna colombiana.

A medida que van apareciendo los relatos, la capa metonímica que alberga el esquema cronológico-temporal del rescate cambia de sentido al añadirle la segunda capa de acontecimientos que amplían su significado por acción de la dominancia tropológica de la metáfora y la sinécdoque, la cual introduce y relaciona nuevos episodios, algunas veces contradictorios o confusos, como el de la comisión europea que iba a negociar el rescate, el del verdadero origen de la operación en la estructura del Ejército, o el del papel del ex-guerrillero en el equipo de oficiales de inteligencia que participaron del rescate. Es en estos episodios en donde se viene a resolver definitivamente el sentido de la Operación Jaque, es decir, en donde se viene a dar el proceso de narrativización como una acción de dotar de sentido a la realidad.

Así, por efecto de la narrativización de lo sucedido el 2 de julio de 2008, surge la idea del fin del conflicto interno colombiano. El modo en que los medios han narrado los acontecimientos hace posible que se produzca esta idea como una forma de representación mediática que instaló en la opinión pública la posibilidad de una derrota militar de las FARC, incluso, de una época que los medios, nuevamente narrativizando, llamaron de post-conflicto.

Finalmente, hay que puntualizar sobre el concepto de narrativización unos aspectos que ayudarán a entenderlo mejor como categoría de análisis apropiada para el estudio y comprensión de los problemas y fenómenos relativos a la representación mediática de la realidad. En primer lugar, hay que diferenciar el concepto de narrativización del concepto de narración. Por narrativización deben entenderse los procesos de construcción de sentido sobre unos acontecimientos pasados que se tienen por verídicos, a partir de la selección, tramado y tropologización de los acontecimientos. Con esto, se elabora un sentido de lo sucedido que se fija como representación de la realidad.

El segundo nivel de análisis es el de la tropología, con el cual se fija el sentido del mismo. Prácticamente, la narrativización surge de las relaciones que se puedan establecer entre estas dos capas, es decir, entre selección-tramado y tropologización. Este acento en el análisis tropológico justifica también que la narrativización se refiera a procesos de representación y no solo de análisis estructural, porque los tropos se comprometen con las formas de imaginar la realidad que tiene el relator o quien produzca el relato ya que actúan como códigos que coordinan la relación de los acontecimientos, por consiguiente, como reglas de estructuración de sentido.

Los tropos no son excluyentes entre sí cuando se les aplica para descubrir cómo están relacionados diferentes acontecimientos en una secuencia narrativa. Esto quiere decir que en un mismo encadenado pueden haber varios tropos, lo que complejiza su diagramación para efectos del análisis, pero aclara bien como se forma el sentido. En este aspecto 
se hace importante resaltar la aparición de tres subcategorías emergentes en el análisis de la tropología. Son las que se definieron como ideas-red, acontecimientos detonadores y condensadores, y lo realacontecido.

Por último, se dirá que estos procesos de representación de la realidad mediante la narrativización de los acontecimientos, no cuestionan si los mismos han sucedido o no en lo que se puede llamar lo real. De algún modo si se cuestionara tan profundamente este concepto, el mismo análisis de la narrativización quedaría sin fondo. Simplemente lo que se cuestiona es la representación que sobre ellos se hace, que sí es construida y no dada, como ha quedado demostrado en la investigación, y que afecta las representaciones presentes que socialmente se construye sobre eventos pasados. En ese orden de ideas, un análisis de la narrativización de cualquier evento, ya sea en los medios o en otros soportes, conecta la investigación de las representaciones de la realidad con los estudios sobre la memoria de lo vivido (Erll, 2012), como un efecto narrativo latente sobre la configuración de lo presente.

\section{Referencia Bibliográfica}

Bal, M. (1996). Teoría de la Narrativa. Madrid: Cátedra.

Erll, A. (2012). Memoria Colectiva y culturas del recuerdo. Estudio introductorio. Bogotá: Uniandes Ediciones.

García, J. (2001). Análisis del Texto Literario. Estudio del texto literario según los modelos de Propp, Greimas, y Bremond. Manizales: Universidad Nacional de Colombia.

Luhmann, N. (2007). La realidad de los medios de masas. México: Editorial Anthropos.

Ricoeur, P. (2007). Tiempo y Narración. Configuración del tiempo en el relato histórico. México: Siglo Ventiuno Editores.
Ricoeur, P. (2006): Teoría de la Interpretación. México: Siglo Veintiuno Editores.

Rincón, O. (2006). Narrativas Mediáticas. O cómo se cuenta la sociedad del entretenimiento. Barcelona: Editorial Gedisa S.A.

Todorov, T. (1971). Literatura y Significación. Barcelona: Editorial Plantea.

White, H. (2005). Metahistoria: La Imaginación Histórica en la Europa del Siglo XIX. México: Fondo de Cultura Económica.

White, H. (1992). El Contenido de la forma: Narrativa, discurso y representación histórica. Barcelona: Paidós.

White, H. (2003). El Texto Histórico como Artefacto Literario. Barcelona: Paidós.

White, H. (2010). Ficción Histórica, historia ficcional y realidad histórica. Buenos Aires: Prometeo.

\section{Notas al lector}

1 Tan solo un mes después de la operación, ya aparecía el primer documento periodístico: el especial de RCN de la Operación Jaque.

2 Sin lugar a dudas la narrativización de la operación Jaque, en la que Ingrid es redimida, se irá a convertir en la primera capa de sentido de una posterior narrativización de la controversia nacional que surgió cuando la ex candidata presidencial demandó al Estado colombiano por su secuestro. Por efecto de esta narrativización, en el imaginario de lo sucedido, Ingrid Betancurt es una beneficiada de la Operación Jaque, es decir, del gobierno, por lo que demandar al Estado es un contrasentido narrativo que no encaja en los roles que una víctima debe tener con respecto al héroe redentor. Posteriormente la ex candidata desistió de la demanda para no controvertir más la opinión pública colombiana. 